\title{
In-Situ Carbon Control in the Preparation of Precursors to Boron Carbide by a Non-Aqueous Solution Technique
}

\author{
Joshua L. Watts ${ }^{1,2^{*}}$, Peter C.Talbot ${ }^{1,2}$, Jose A. Alarco ${ }^{1,2}$ and Ian D. R. Mackinnon ${ }^{1}$ \\ 1. Institute for Future Environments, Queensland University of Technology, Brisbane 4001, Australia \\ 2. Science and Engineering Faculty, School of Chemistry, Queensland University of Technology, Brisbane 4001, Australia
}

\begin{abstract}
Synthesis of high quality boron carbide $\left(\mathrm{B}_{4} \mathrm{C}\right)$ powders is achieved by carbothermal reduction of boron oxide $\left(\mathrm{B}_{2} \mathrm{O}_{3}\right)$ from a condensed boric acid $\left(\mathrm{H}_{3} \mathrm{BO}_{3}\right)$ /polyvinyl acetate (PVAc) product. Precursor solutions are prepared via free radical polymerisation of vinyl acetate (VA) monomer in methanol in the presence of dissolved $\mathrm{H}_{3} \mathrm{BO}_{3}$. A condensed product is then formed by flash evaporation under vacuum. As excess VA monomer is removed at the evaporation step, the polymerisation time is used to manage availability of carbon for reaction. This control of carbon facilitates dispersion of $\mathrm{H}_{3} \mathrm{BO}_{3}$ in solution due to the presence of residual VA monomer. $\mathrm{B}_{4} \mathrm{C}$ powders with very low residual carbon are formed at temperatures as low as $1,250{ }^{\circ} \mathrm{C}$ with a 4 hour residence time.
\end{abstract}

Key words: Boron carbide, solution synthesis, polymerisation, poly-vinyl acetate, boric acid.

\section{Introduction}

Boron carbide is used in a wide range of engineering applications due to a combination of properties including high hardness, a high resistance to chemical corrosion, a high melting point and a low specific weight. Boron carbide in many forms-as powders, sintered billets and coatings-is used as wear resistant refractories, as a coating for cutting tools, for ballistic applications such as armour plating and as a neutron absorber. Bulk industrial synthesis methods are commonly undertaken at high temperature, followed by milling and hot pressing and/or sintering to shape a product $[1,2]$. However, the formation of excess free carbon during these synthesis methods is problematic $[2,3]$.

Although $\mathrm{B}_{4} \mathrm{C}$ can be synthesised by directly reacting elemental boron and carbon [4], this technique is rarely used due to the high costs of the purified elements. $\mathrm{B}_{4} \mathrm{C}$ is also made by a magnesiothermal reaction wherein magnesium metal is used to reduce

Corresponding author: Joshua L. Watts, Ph.D. candidate, research fields: materials science, boron chemistry, ceramic synthesis and boron carbide characterization. E-mail: joshua.watts@qut.edu.au. boron oxide for subsequent reaction with a carbon source. However, acid washing is required to remove magnesium contaminants [1]. The most widely used commercial technique for producing $\mathrm{B}_{4} \mathrm{C}$ is the reduction of $\mathrm{H}_{3} \mathrm{BO}_{3}$ with carbon black (referred to as the carbothermal method) at $\sim 1,750{ }^{\circ} \mathrm{C}$ in electric arc furnaces [5].

The overall reaction mechanism for the carbothermal process is:

$$
4 \mathrm{H}_{3} \mathrm{BO}_{3}+7 \mathrm{C} \rightarrow \mathrm{B}_{4} \mathrm{C}+6 \mathrm{CO}+6 \mathrm{H}_{2} \mathrm{O}
$$

The commercial method for carbothermal reduction results in high amounts of residual carbon that adversely affect the properties of a final or formed product and thus further processing is required to remove this carbon. For example, the coarse-grained boron carbide powder requires intensive milling to generate a finer powder suitable for sintering; the intense milling also results in contamination from grinding media. Because of these issues, research is focused on alternative lower temperature synthesis methods that result in a fine powder with less residual carbon [3, 6-8]. The use of catalysts to remove residual carbon has been explored [9], but such methods result 
in contamination by the catalysts or require expensive precursor materials. Micron sized $\mathrm{B}_{4} \mathrm{C}$ powder with no residual carbon has been successfully formed by mixing excess $\mathrm{B}_{2} \mathrm{O}_{3}$ powder and carbon under inert conditions [10]. However, the temperature required for complete reaction is still high at $1,800{ }^{\circ} \mathrm{C}$.

Solution based synthesis offers a facile method for the production of boron carbides with potential to form a fine powder at relatively low temperatures. Complete dissolution of precursor components, if achieved, affords a high degree of homogeneity in subsequently condensed products. This feature may allow enhanced reaction kinetics and greater control over residual-free phase formation. By dissolving boron compounds and a suitable carbon source in solution, a condensed precursor powder may be achieved by evaporation of the solvent.

Early attempts to synthesise boron carbides, including $\mathrm{B}_{4} \mathrm{C}$, using solution-based techniques include the work by Weimer and colleagues which required high calcination temperatures [11-13]. Other methods include the application of pressure during calcination $[14,15]$ or specialised precursors to form boron carbides [16, 17]. In many cases, the presence of residual carbon is evident [11, 12, 14, 15, 17]. Recently, Yanase et al. report production of $\mathrm{B}_{4} \mathrm{C}$ at $1,300{ }^{\circ} \mathrm{C}$ with low residual carbon using mixed aqueous PVAl (polyvinyl alcohol) and $\mathrm{H}_{3} \mathrm{BO}_{3}$ solutions [18]. Subsequently, Kakiage et al. improved upon the removal of residual carbon but with a long residence time of $20 \mathrm{~h}$ at $1,300{ }^{\circ} \mathrm{C} \mathrm{[3]}$.

Kakiage et al. $[6,7]$ show that water soluble carbon sources (glycerin, mannitol) when mixed with aqueous $\mathrm{H}_{3} \mathrm{BO}_{3}$ solutions are suitable precursors for formation of $\mathrm{B}_{4} \mathrm{C}$. With glycerin, nearly carbon-free $\mathrm{B}_{4} \mathrm{C}$ was formed at $1,250{ }^{\circ} \mathrm{C}$ with a residence time of $5 \mathrm{~h}$ [6]. With mannitol as precursor and $\mathrm{H}_{3} \mathrm{BO}_{3}$ in excess, nearly carbon-free $\mathrm{B}_{4} \mathrm{C}$ is obtained at $1,300^{\circ} \mathrm{C}$ with a $5 \mathrm{~h}$ residence time [7]. However, in both cases, optimised synthesis with excess carbon required a pyrolysis step in air to remove this carbon before calcination. We report here an improved solution-based synthesis for boron carbide that utilises the polymerisation of a short-chain monomer in the presence of completely dissolved $\mathrm{H}_{3} \mathrm{BO}_{3}$ in a non-aqueous solvent such as methanol.

\section{Experimental Methods}

Precursor powders are prepared by a four stage process as follows: (i) dissolution of $\mathrm{H}_{3} \mathrm{BO}_{3}$ and VA monomer in methanol $(\mathrm{MeOH})$; (ii) a polymerisation stage under $\mathrm{N}_{2}$ inert atmosphere to generate PVAc; (iii) a flash evaporation stage to remove the solvent/excess monomer to form the dry $\mathrm{PVAc} / \mathrm{H}_{3} \mathrm{BO}_{3}$ precursor powder; and (iv) a pre-treatment stage where various atmospheric conditions are trialled. Pre-treated powders are then calcined in $\mathrm{Ar}$ to form the final $\mathrm{B}_{4} \mathrm{C}$ product. Precursor powders formed via flash evaporation after the polymerisation stage are referred to as 'PVAcB' powders. A summary of the process stages is shown in Fig. 1 including the characterisation

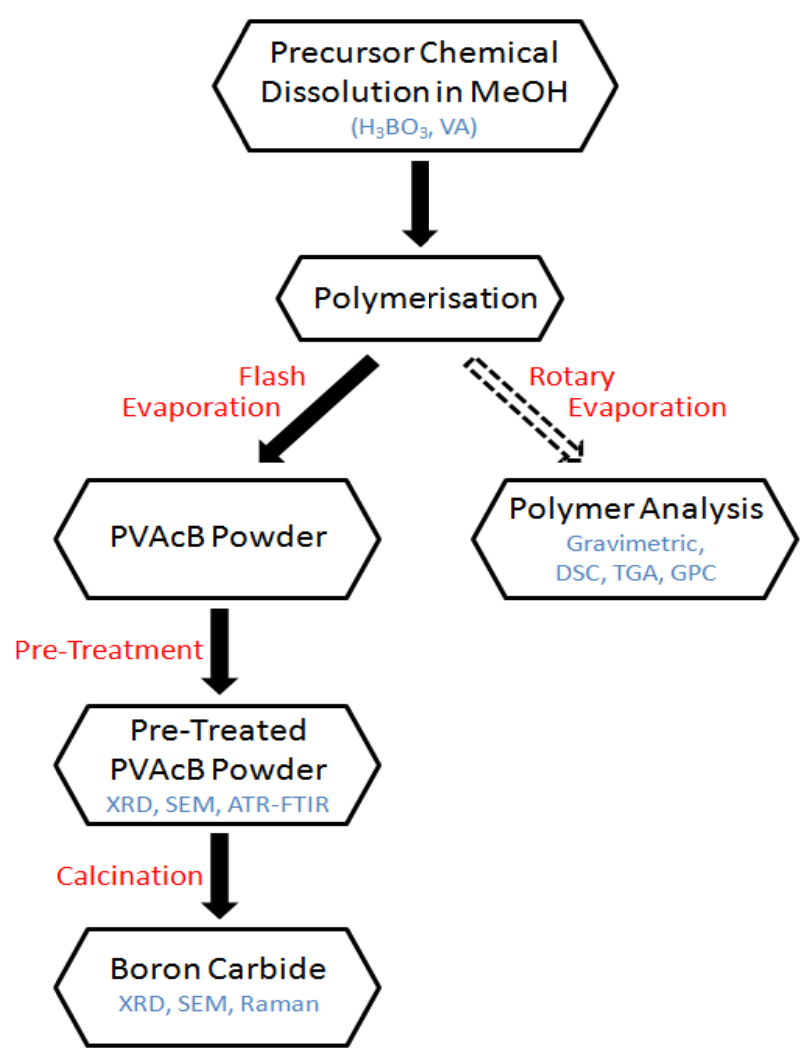

Fig. 1 Processing stages with accompanying characterisation techniques. 
techniques employed at each stage for reference. Analysis of generated polymers and polymer $/ \mathrm{H}_{3} \mathrm{BO}_{3}$ products was carried out on powders formed from solvent removal by a rotary evaporator.

\subsection{Starting Materials}

$\mathrm{H}_{3} \mathrm{BO}_{3}(99.5 \%)$, VA monomer ( $\left.\geq 99 \%\right)$, and benzoyl peroxide (75\%, remainder water) from Sigma-Aldrich, AR grade $\mathrm{MeOH}$ (99.8\%) from Chem-Supply and basic alumina (90 active) from Merck were used as received.

\subsection{Polymers}

\subsubsection{Synthesis}

$50 \mathrm{~g}$ of VA was added to $20 \mathrm{~g}$ of $\mathrm{MeOH}$ and passed over a column of basic alumina to remove inhibitor. $24.73 \mathrm{~g}$ of $\mathrm{H}_{3} \mathrm{BO}_{3}$ was then dissolved in $100 \mathrm{~g}$ of methanol and added slowly to the VA solution. $1.33 \mathrm{~g}$ of $\mathrm{BzO}$ (benzoyl peroxide) initiator compound was then added and dissolved. A viscous clear colourless solution was obtained. The solution was then bubbled with $\mathrm{N}_{2}$ for 30 min to remove $\mathrm{O}_{2}$ and then heated to $65{ }^{\circ} \mathrm{C}$ under $\mathrm{N}_{2}$ atmosphere to initiate polymerisation. Separate polymerisation reactions were then held at $65{ }^{\circ} \mathrm{C}$ for a range of times under $\mathrm{N}_{2}$ atmosphere. Polymerisation times of 1,6 and $18 \mathrm{~h}$ are the focus of this paper as these times yielded relevant results.

\subsubsection{Characterisation}

The peak molecular weight $\left(M_{p}\right)$, weight average molecular weight $\left(M_{w}\right)$ and the PDI (polydispersity index) of synthesised polymer precursors were determined via GPC (gel permeation chromatography) using a Waters 2487 absorbance detector in series with a Waters 2414 refractive index detector. Chromatography treatment used three consecutive phenomenex, phenogel $5 \mu \mathrm{m}$ columns $(300 \times 7.8 \mathrm{~mm}$; $104 \AA, 103 \AA, 50 \AA)$ operating at $30{ }^{\circ} \mathrm{C}$ using tetrahydrofuran as eluent at a flow rate of $1 \mathrm{~mL} / \mathrm{min}$. These columns were preceded by a Phenomenex $5 \mu \mathrm{m}$ Linear Mixed Bed guard column $(50 \times 7.8 \mathrm{~mm})$. Polymer weights were determined by gravimetric analysis; $\mathrm{H}_{3} \mathrm{BO}_{3}$ was not added to the solution before polymerisation due to the azeotrope it forms with methanol which leads to loss of $\mathrm{H}_{3} \mathrm{BO}_{3}$ during solvent evaporation and hence errors in the final weight measurement of the polymer. After polymerisation and solvent removal using a rotary evaporator, the polymer was dried overnight in a vacuum oven at $100{ }^{\circ} \mathrm{C}$ and weighed. DSC (Differential scanning calorimetry) and TGA (thermogravimetric) data were collected simultaneously using a Netzsch STA-449F3 instrument.

\subsection{PVAcB Powders}

\subsubsection{Preparation}

PVAcB powders were formed by flash evaporation of solutions prepared as per section 2.2.1 under vacuum within $24 \mathrm{~h}$ of polymerisation. The dry PVAcB powder obtained was then ring milled for $10 \mathrm{~s}$ at $750 \mathrm{rpm}$. The PVAcB powder was then pre-treated at $450{ }^{\circ} \mathrm{C}$ or $550{ }^{\circ} \mathrm{C}$ for 1 to $2 \mathrm{~h}$ under three different atmospheric conditions: (i) $3 \mathrm{~L} / \mathrm{m}$ Ar flow (full Ar flow), (ii) $\mathrm{Ar}$ flow with $4 \times 10^{-1}$ bar absolute pressure (partial vacuum) or (iii) $10^{-3}$ bar absolute pressure with no $\mathrm{Ar}$ flow (full vacuum), in order to determine optimum phase formation conditions. A summary of these pre-treatment conditions for the PVAcB powders is given in Table 1. The prefixes PV, A and V reflect the atmospheric conditions used (partial vacuum, full $\mathrm{Ar}$ flow and full vacuum, respectively).

Table 1 Treatment conditions for condensed PVAcB powders at different polymerisation times.

\begin{tabular}{|c|c|c|c|c|c|c|c|}
\hline \multirow{3}{*}{\multicolumn{2}{|c|}{$\begin{array}{l}\text { PRE-TREATMENT CONDITIONS } \\
(\mathrm{PV})=\mathrm{Ar} \text { flow, } 4 \times 10^{-1} \mathrm{bar} \\
(\mathrm{A})=3 \mathrm{~L} / \mathrm{m} \text { Ar flow } \\
(\mathrm{V})=10^{-3} \mathrm{bar}\end{array}$}} & \multicolumn{3}{|c|}{ Partial vacuum (PV) } & \multicolumn{2}{|c|}{ Full Ar flow (A) } & \multirow{2}{*}{$\begin{array}{c}\text { Full vacuum }(\mathrm{V}) \\
\text { Poly time }\end{array}$} \\
\hline & & \multicolumn{3}{|c|}{ Polymerisation time } & \multicolumn{2}{|c|}{ Polymerisation time } & \\
\hline & & $1 \mathrm{~h}$ & $6 \mathrm{~h}$ & $18 \mathrm{~h}$ & $1 \mathrm{~h}$ & $6 \mathrm{~h}$ & $6 \mathrm{~h}$ \\
\hline \multirow{3}{*}{$\begin{array}{l}\text { Firing time and } \\
\text { temperature }\end{array}$} & $1 \mathrm{~h} 450^{\circ} \mathrm{C}$ & & & & & A6-1-450 & \\
\hline & $1 \mathrm{~h} 550^{\circ} \mathrm{C}$ & PV1-1-550 & PV6-1-550 & PV18-1-550 & & A6-1-550 & V6-1-550 \\
\hline & $2 \mathrm{~h} 550^{\circ} \mathrm{C}$ & \multicolumn{6}{|c|}{ A $1-2-550$} \\
\hline
\end{tabular}


Table 2 Summary of data collected by GPC analysis for as-synthesised PVAc.

\begin{tabular}{llll}
\hline Polymerisation Time & $M_{P}$ & $M_{w}$ & $P D I$ \\
\hline $1 \mathrm{~h}$ & 36,151 & 82,037 & 2.60 \\
$6 \mathrm{~h}$ & 26,623 & 28,045 & 2.40 \\
$18 \mathrm{~h}$ & 23,233 & 22,155 & 2.78 \\
\hline
\end{tabular}

\subsubsection{Calcination}

Pre-treated PVAcB powders were again ring milled and placed in a graphite crucible and calcined at $1,250-1,400{ }^{\circ} \mathrm{C}$ with a ramp rate of $25^{\circ} \mathrm{C} / \mathrm{min}$ for 1 to 4 $\mathrm{h}$ under $3 \mathrm{~L} / \mathrm{m}$ Ar flow.

\subsubsection{Characterization}

Pre-treated and calcined PVAcB powders were analysed using XRD (X-ray diffraction), SEM (scanning electron microscopy), ATR-FTIR (attenuated total reflectance Fourier transform infrared spectroscopy) and Raman spectroscopy. To analyse powders with the boron component removed, a hot DI (deionised) water wash was employed. XRD measurements were collected using a PANalytical X'Pert PRO diffractometer with Co K $\alpha 1$ radiation. SEM images were obtained using a JEOL JSM-7001 field emission scanning electron microscope. ATR-FTIR measurements were taken with a Nicolet iS50 FT-IR spectrometer while Raman spectra were collected with a Renishaw System 1000 Raman Microscope with a $40 \mathrm{~s}$ exposure per scan using a 633 $\mathrm{nm}$ excitation wavelength from a HeNe laser. The laser power at the sample was $\sim 2 \mathrm{~mW}$ focused to a spot size of $\sim 1 \mu \mathrm{m}$ through a x 50 objective lens. All spectra are normalized to the area of the peak at $1,088 \mathrm{~cm}^{-1}$ commonly identified as the breathing mode of the boron icosahedra in boron carbide $[19,20]$.

\section{Results}

Experiments were undertaken to characterise the starting materials, the formed PVAc polymer, polymer $/ \mathrm{H}_{3} \mathrm{BO}_{3}$ mixture, $\mathrm{PVAcB}$ powders and the final $\mathrm{B}_{4} \mathrm{C}$ product. Table 1 summarizes the pre-treatment conditions for each sample.

\subsection{Polymer Analysis}

The weights of as-synthesised PVAc for 1, 6 and
$18 \mathrm{~h}$ polymerisation times determined via gravimetric analysis are $13.20 \mathrm{~g}, 34.73 \mathrm{~g}$ and $41.05 \mathrm{~g}$, respectively. The molecular weights, $M_{p}$ and $M_{w}$ as well as the PDI of PVAc with polymerisation times of 1,6 and $18 \mathrm{~h}$ determined by GPC analysis are summarised in Table 2 . Polydispersity is a measure of polymer molecular mass distribution given by PDI $=M_{w} / M_{n}$, where, $M_{n}$ is the number average molecular weight. These molecular weight determinations reveal a decrease in $M_{p}$ and $M_{w}$ values with longer polymerisation time.

DSC and TGA characterisation was performed on pure $\mathrm{H}_{3} \mathrm{BO}_{3}, 1 \mathrm{~h}$ polymerised PVAc as well as PVAc polymerised for $1 \mathrm{~h}$ in the presence $\mathrm{H}_{3} \mathrm{BO}_{3}$ for comparison. The results of this characterisation are shown in Fig. 2 and Fig. 3.

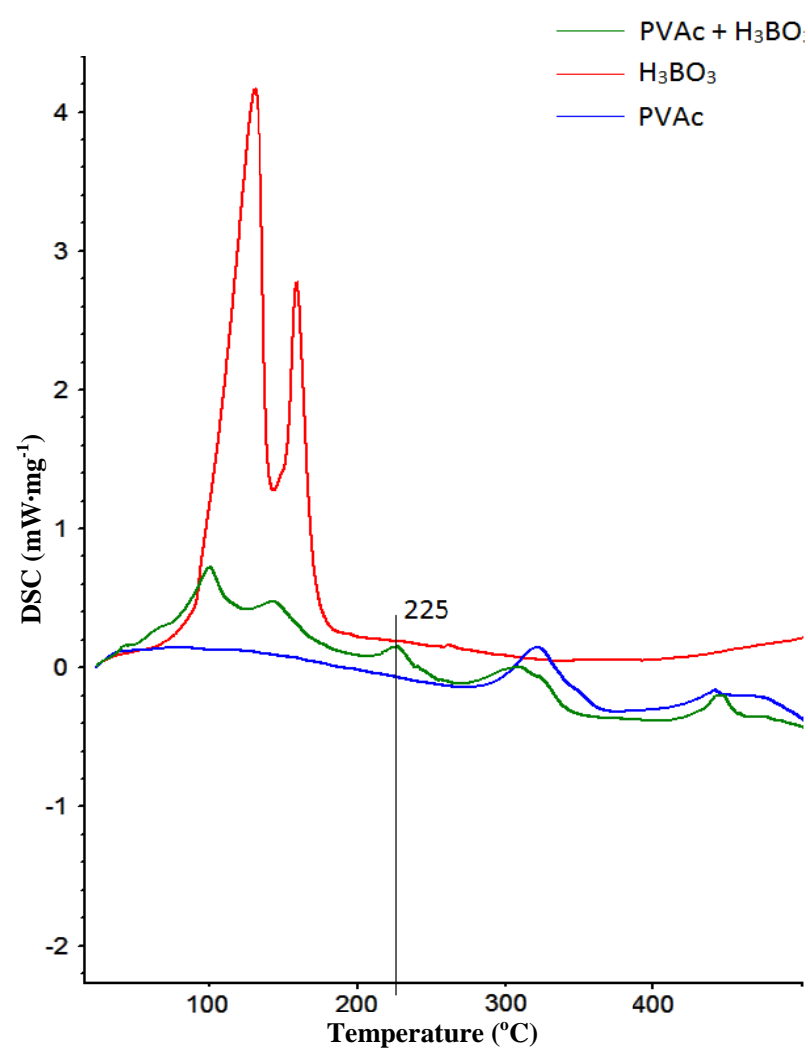

Fig. 2 DSC data for $\mathrm{H}_{3} \mathrm{BO}_{3}, 1 \mathrm{~h}$ polymerised PVAc and $1 \mathrm{~h}$ polymerised PVAc in the presence of $\mathrm{H}_{3} \mathrm{BO}_{3}$. 

a Non-Aqueous Solution Technique

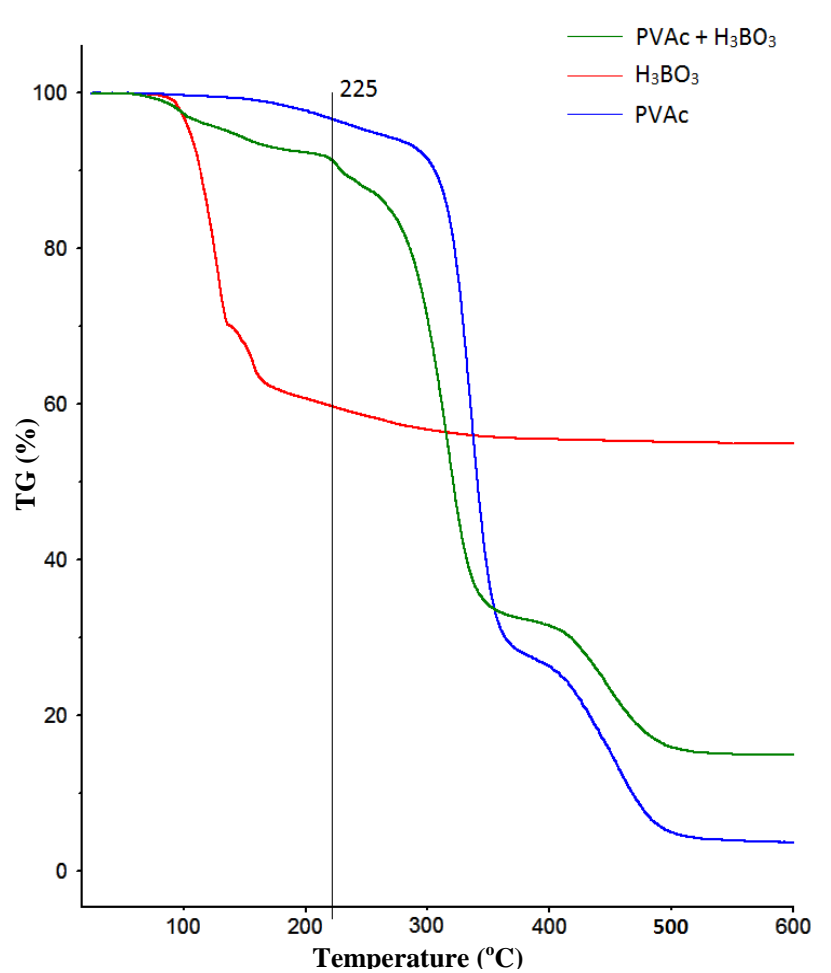

Fig. 3 TGA data for $\mathrm{H}_{3} \mathrm{BO}_{3}$, $1 \mathrm{~h}$ polymerised PVAc and $1 \mathrm{~h}$ polymerised PVAc in the presence of $\mathrm{H}_{3} \mathrm{BO}_{3}$.

\subsection{PVAcB Powder Analysis}

SEM images of typical pre-treated PVAcB powders before and after washing with hot DI water are shown in Fig. 4.

Note the fine scale circular features ranging in size from $100 \mathrm{~nm}$ to $\sim 1 \mu \mathrm{m}$. Close inspection reveals very fine ( $\sim 10 \mathrm{~nm}$ cross section) string-like features coating the carbon matrix (highlighted by the white arrow in Fig. 4b).

PVAcB powders were analysed by XRD after pre-treatment. A typical XRD pattern of this powder is shown in Fig. 5 and compared against XRD patterns of $\mathrm{H}_{3} \mathrm{BO}$ and $\mathrm{B}_{2} \mathrm{O}_{3}$. This comparison suggests that the string-like features observed in the SEM images of unwashed pre-treated PVAcB powders (Fig. 4b) are $\mathrm{H}_{3} \mathrm{BO}_{3}$.

The ATR-FTIR transmittance spectrum of a typical unwashed pre-treated PVAcB powder compared with pure $\mathrm{H}_{3} \mathrm{BO}_{3}$ is shown in Fig. 6. The spectra are nearly identical indicating that the signal from the $\mathrm{H}_{3} \mathrm{BO}_{3}$ is far more intense than any response from the carbon

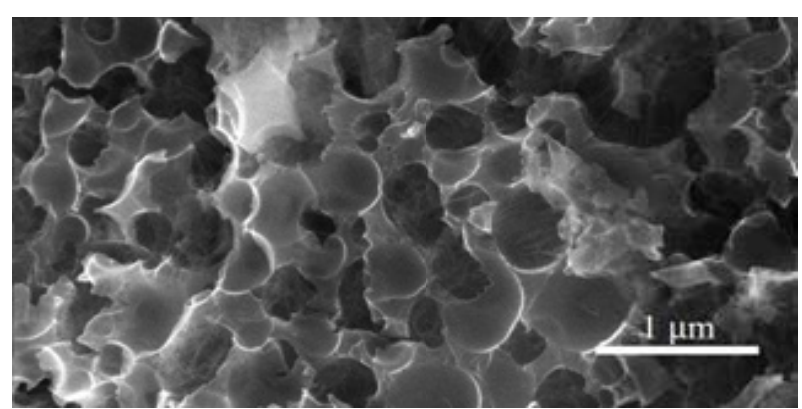

(a)

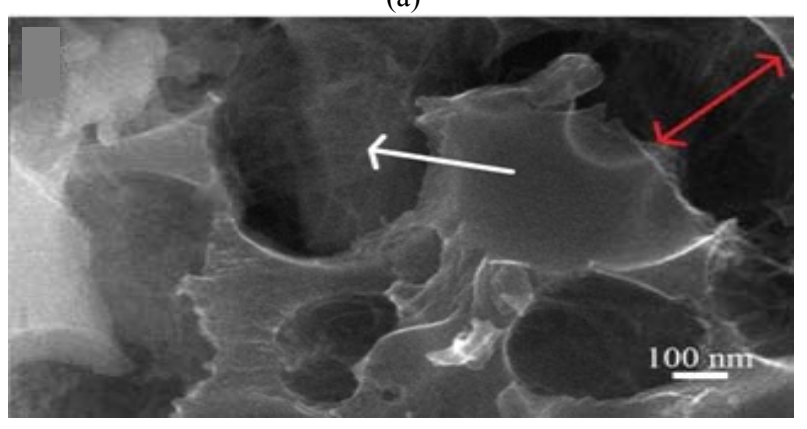

(b)

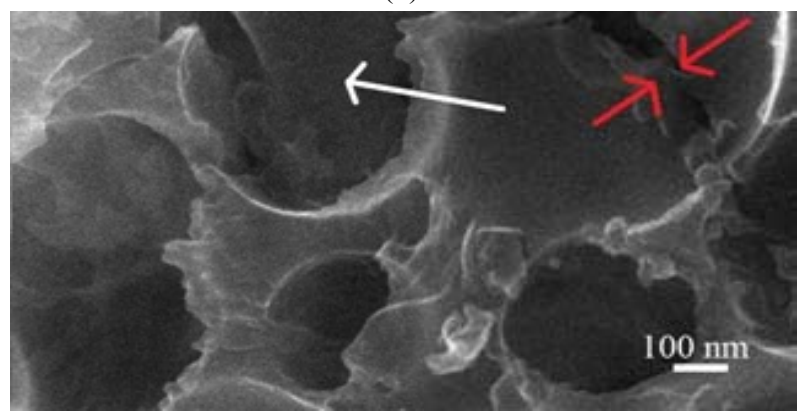

(c)

Fig. 4 SEM images of typical pre-treated PVAcB powder before $(a, b)$ and after (c) washing. The red arrows highlight a position where a crack has recombined due to the removal of the boron component and the white arrows highlight the presence and subsequent removal of the $\mathrm{H}_{3} \mathrm{BO}_{3}$ 'strings'.

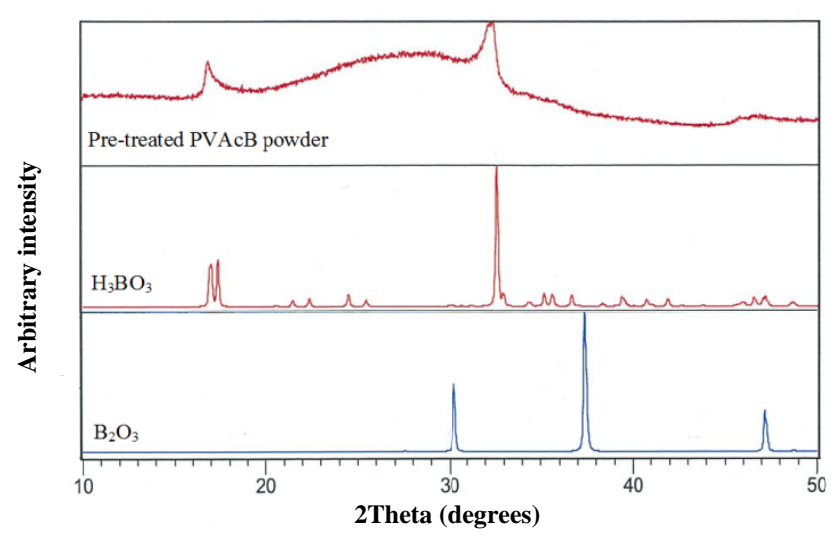

Fig. 5 XRD trace comparison of a typical PVAcB powder after pre-treatment, $\mathrm{H}_{3} \mathrm{BO}_{3}$ (ICSD ref. 98-006-1354) and $\mathrm{B}_{2} \mathrm{O}_{3}$ (ICSD ref. 98-001-6021). 


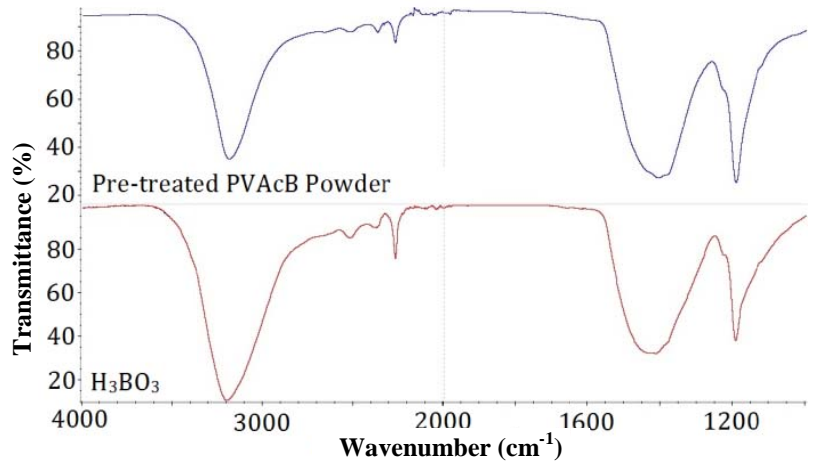

Fig. 6 ATR-FTIR scan comparison of unwashed A1-2-550 powder and boric acid.

matrix. This result also corroborates the information gained from XRD analysis. ATR-FTIR of washed PVAcB powders with the boron component removed is a match for an aromatic hydrocarbon.

\subsection{Processing Conditions: Formation of $\mathrm{B}_{4} \mathrm{C}$}

Synthesis conditions were systematically evaluated to establish the key determinants for optimised formation of a phase pure, carbon-free $\mathrm{B}_{4} \mathrm{C}$ product. These conditions included polymerisation time, pre-treatment atmospheric conditions and calcination time. For each suite of conditions, the same heating rate has been used at the particular temperature range.

\subsubsection{Polymerisation Time}

PVAcB powders of 1,6 and $18 \mathrm{~h}$ polymerisation times that were pre-treated for $1 \mathrm{~h}$ at $550{ }^{\circ} \mathrm{C}$ with partial vacuum conditions (PV1-1-550, PV6-1-550 and PV18-1-550, respectively) were analysed by XRD after calcination for $1 \mathrm{~h}$ (Fig. 7) and $2 \mathrm{~h}$ (Fig. 8) at $1,400{ }^{\circ} \mathrm{C}$. Note in Fig. 7 the difference in relative proportions of carbon results from different polymerisation times. The proportion of carbon is the lowest for PVAcB powder with a $1 \mathrm{~h}$ polymerisation time.

\subsubsection{Pre-treatment Atmosphere}

A typical XRD pattern of $\mathrm{PVAcB}$ powder calcined at $1,400{ }^{\circ} \mathrm{C}$ for $1 \mathrm{~h}$ without pre-treatment is shown in Fig. 9. Note the excess carbon and absence of an $\mathrm{H}_{3} \mathrm{BO}_{3}$ phase.

PVAcB powders with 6 hour polymerisation time pre-treated under full Ar flow, partial vacuum and full

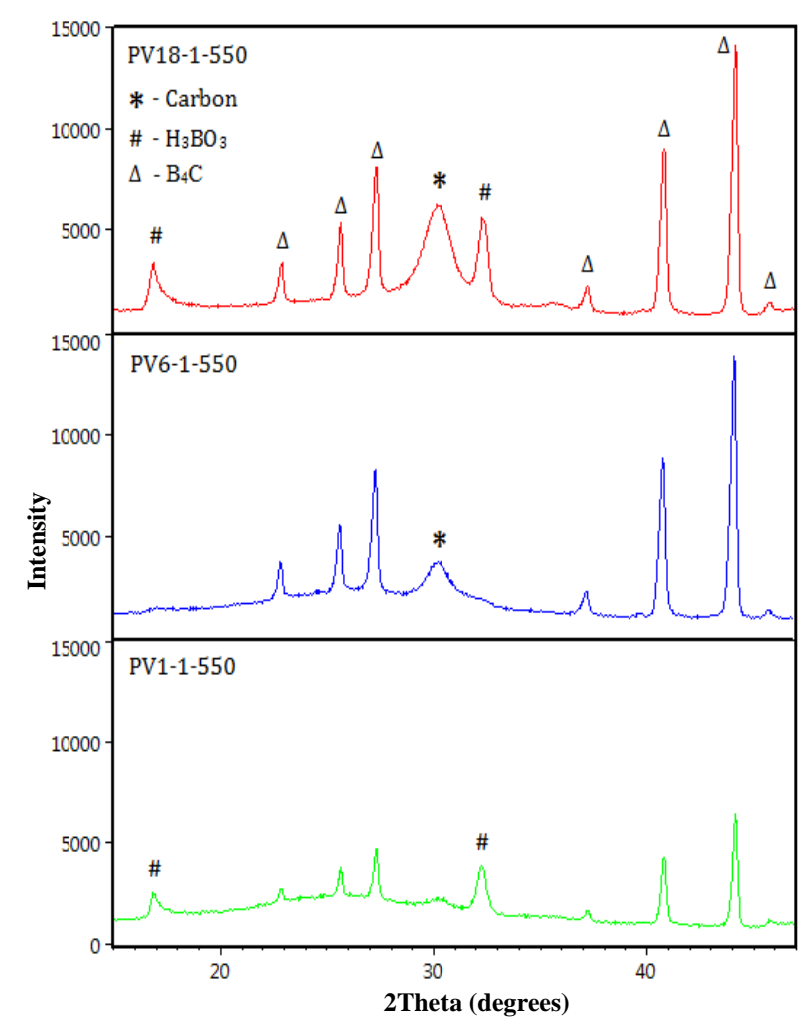

Fig. 7 PVAcB powders of varying polymerisation times pre-treated under $4 \times 10^{-1}$ partial vacuum and Ar flow calcined at $1,400{ }^{\circ} \mathrm{C}$ for $1 \mathrm{~h}$.

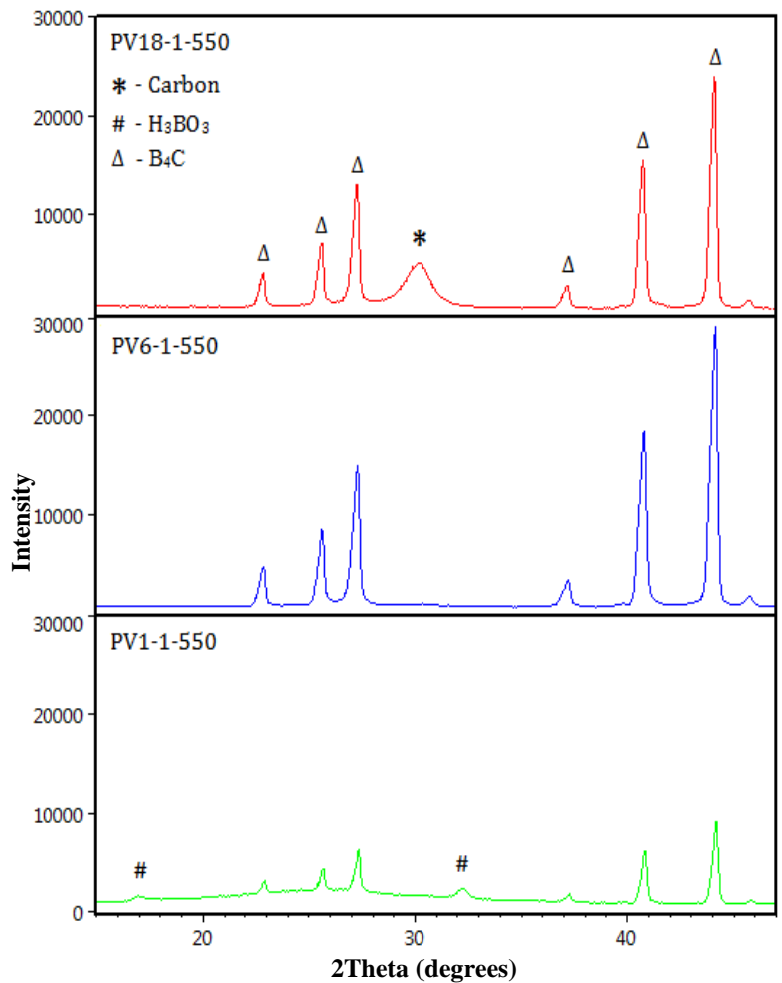

Fig. 8 PVAcB powders of varying polymerisation times pre-treated under $4 \times 10^{-1}$ partial vacuum and Ar flow calcined at $1,400{ }^{\circ} \mathrm{C}$ for $2 \mathrm{~h}$. 


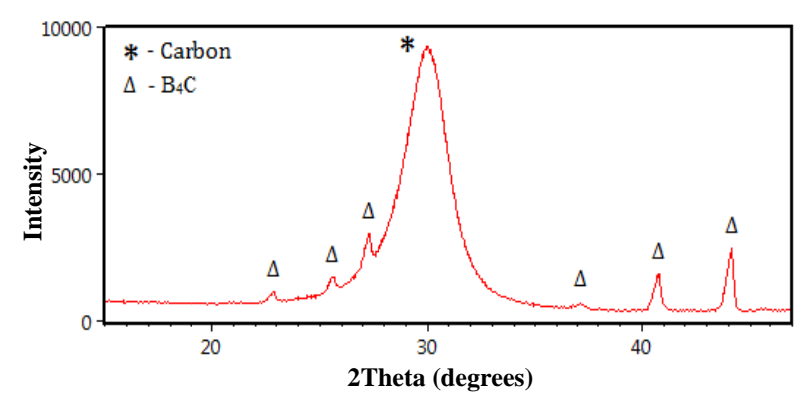

Fig. 9 XRD pattern of typical PVAcB powder calcined at $1,400{ }^{\circ} \mathrm{C}$ for $1 \mathrm{~h}$ without pre-treatment.

vacuum conditions (A6-1-550, PV6-1-550 and V6-1-550 respectively) were calcined to reaction completion to evaluate the influence of vacuum on the carbon precursor component. XRD traces of the calcined products are shown in Fig. 10; note the substantial difference between traces due to the variation in pressure. The time required to reach complete $\mathrm{B}_{4} \mathrm{C}$ formation is reduced by $1 \mathrm{~h}$ for A6-1-550 PVAcB powder.

\subsubsection{Optimisation}

PV6-1-550 PVAcB powder was also calcined for 1, 2, 3, and $4 \mathrm{~h}$ under $3 \mathrm{~L} / \mathrm{m} \mathrm{Ar}$ flow at $1,250{ }^{\circ} \mathrm{C}$ to demonstrate that a lower calcination temperature is possible, data shown in Fig. 6 and Fig. 7 suggest that material polymerised for six hours has an optimum carbon-boron ratio to form near carbon-free $\mathrm{B}_{4} \mathrm{C}$. The XRD patterns of these calcined powders are shown in Fig. 11.

Because residual carbon is observed in calcined product formed from PVAcB powders pre-treated under full Ar flow conditions at atmospheric pressure (see A6-1-550, Fig. 10), a reduction of the polymerisation time to $1 \mathrm{~h}$ is possible. XRD traces of 1 $\mathrm{h}$ polymerised $\mathrm{PVAcB}$ powder pre-treated under full Ar flow (A1-2-550) calcined at $1,400{ }^{\circ} \mathrm{C}$ are shown in Fig. 12 and demonstrate that a $2 \mathrm{~h}$ calcination is sufficient for the formation of the near carbon-free product.

\subsection{B4C Product}

\subsubsection{SEM}

The morphologies of near carbon-free $\mathrm{B}_{4} \mathrm{C}$ (calcined

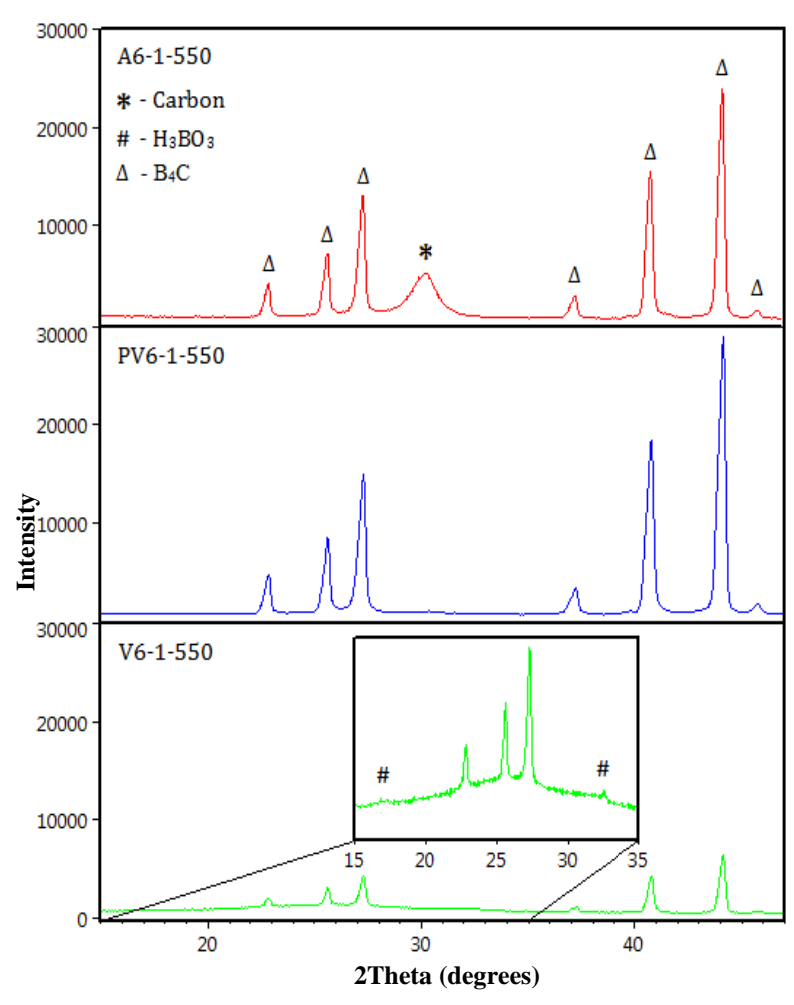

Fig. 10 V6-1-550, PV6-1-550 and A6-1-550 PVAcB powders taken to phase formation completion (A6-1-550 = 1,400 ${ }^{\circ} \mathrm{C}$ for $1 \mathrm{~h}, \mathrm{PV6}-1-550$ and V6-1-550 = 1400 ${ }^{\circ} \mathrm{C}$ for $2 \mathrm{~h}$ ) illustrating the effect of vacuum.

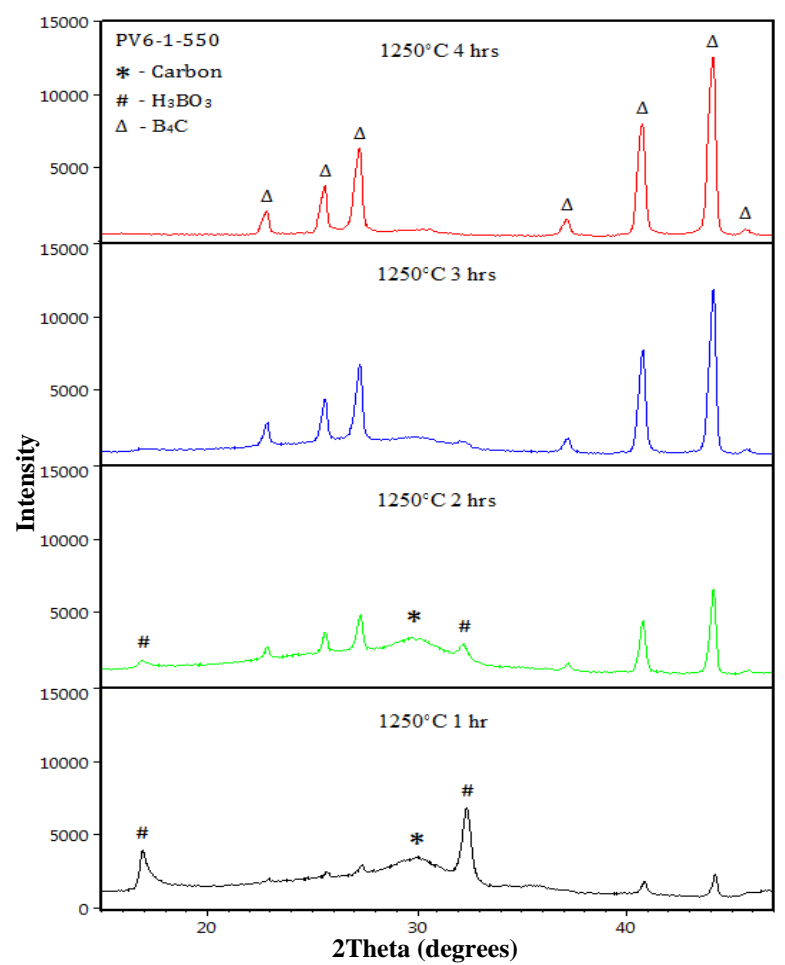

Fig. 11 PV6-1-550 PVAcB powder calcined at 1,250 ${ }^{\circ} \mathrm{C}$ for 1, 2, 3 and $4 \mathrm{~h}$ under $3 \mathrm{~L} / \mathrm{m}$ Ar flow. 
from A1-2-550 PVAcB powder at $1400{ }^{\circ} \mathrm{C}$ for $2 \mathrm{~h}$ ) and $\mathrm{B}_{4} \mathrm{C}$ with residual carbon (calcined from PV18-1-550 PVAcB powder at $1400{ }^{\circ} \mathrm{C}$ for $2 \mathrm{~h}$ ) are shown in Fig. 13a and Fig. 13b, respectively. In Fig. 13a, well-formed euhedral grains range in size from $\sim 1 \mu \mathrm{m}$ to $10 \mu \mathrm{m}$ in size. In Fig. 13b, similar euhedral particles, but with a smaller size range (from $<1 \mu \mathrm{m}$ to $\sim 5 \mu \mathrm{m}$ ), are shown. The inset in Fig. 13b shows residual carbon as sub-micron particles on the surface of $\mathrm{B}_{4} \mathrm{C}$ grains.

\subsubsection{Raman Spectra}

Raman spectra from three different $\mathrm{B}_{4} \mathrm{C}$ samples corresponding to those identified in Fig. 8 (calcined from PV18-1-550, PV6-1-550 and PV1-1-550 PVAcB powders for $2 \mathrm{~h}$ at $1,400{ }^{\circ} \mathrm{C}$ ) are shown in Fig. 14. Each spectrum is from different locations on individual grains in each sample. For each sample, up to 20 different spectra are obtained under the same experimental conditions. Three representative spectra from each sample are shown in Fig. 14.

In Fig. 14, peaks at $1,340 \mathrm{~cm}^{-1}$ and $1,589 \mathrm{~cm}^{-1}$ are characteristic signatures of residual carbon [21]. The intensity of these peaks indicates the relative presence or absence of residual carbon within the sample. Peaks at lower wavenumber between $250 \mathrm{~cm}^{-1}$ and $400 \mathrm{~cm}^{-1}$ are known to vary in intensity dependent on the carbon content within the actual $\mathrm{B}_{4} \mathrm{C}$ crystal structure [19]. In Fig. 14, spectra for sample PV1-1-550 show very low

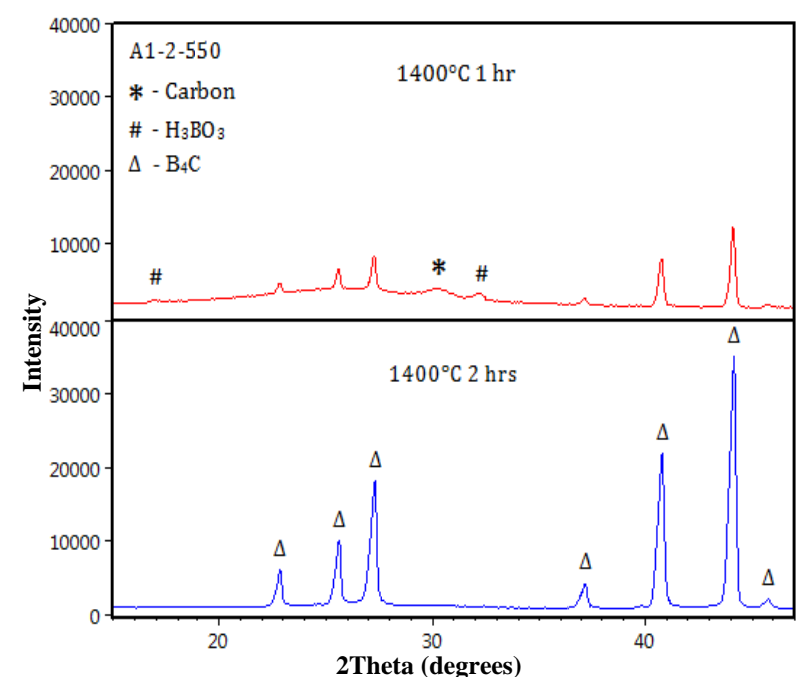

Fig. 12 A1-2-550 PVAcB powder calcined at $1,400{ }^{\circ} \mathrm{C}$ for 1 and $2 \mathrm{~h}$ under $3 \mathrm{~L} / \mathrm{m}$ Ar flow.

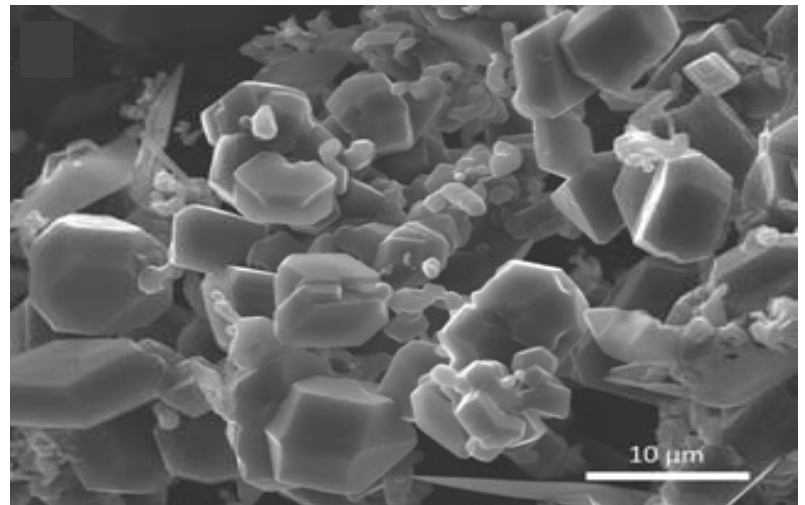

(a)

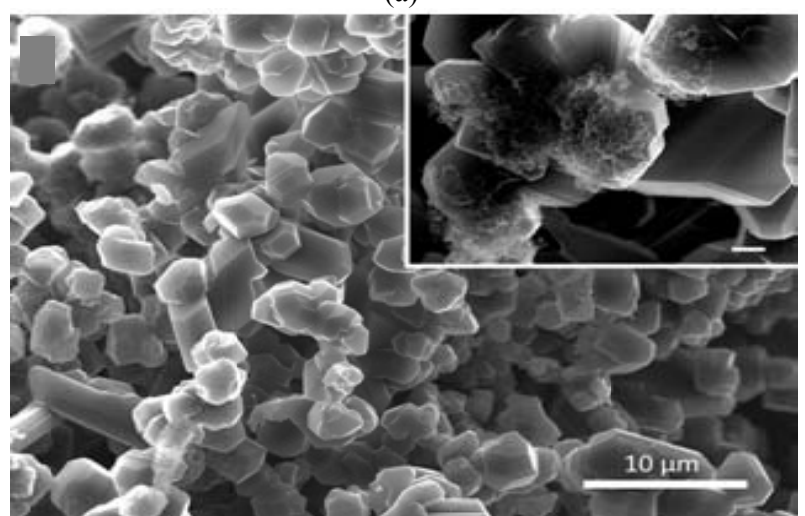

(b)

Fig. 13 SEM images of $\mathrm{B}_{4} \mathrm{C}$ powder calcined at $1400{ }^{\circ} \mathrm{C}$ for 2 h from A1-2-550 (a) and PV18-1-550 (b) PVAcB powders at the same magnification. The smaller particle size of the sample in $b$ is apparent. The inset of Fig. 13b shows the presence of residual carbon (scale bar $1 \mu \mathrm{m}$ ).

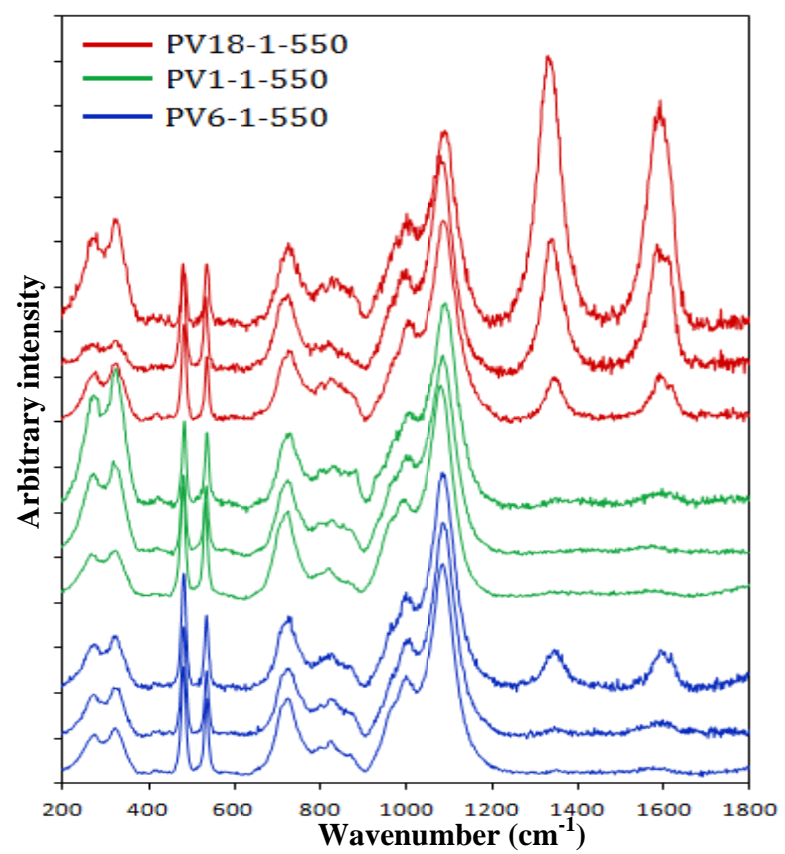

Fig. 14 Raman spectra of $\mathrm{B}_{4} \mathrm{C}$ powders calcined from PV18-1-550, PV6-1-550 and PV1-1-550 PVAcB powders. 
signatures for residual carbon. This qualitative result is consistent with XRD data shown in Fig. 8. Similarly, the majority of grains analysed in sample PV6-1-550 also show a low residual carbon signature using Raman spectroscopy. Sample PV18-1-550 shows a consistently high number of grains with high residual carbon content which is also reflected in the XRD pattern obtained on the bulk sample.

\section{Discussion}

\subsection{Polymerisation Characteristics}

Gravimetric analysis was employed to quantify the amount of polymer formed for polymerisation times of 1,6 and $18 \mathrm{~h}$. A substantial increase in the final PVAc weight was observed between 1 and $6 \mathrm{~h}$ polymerisations. After $18 \mathrm{~h}$, only a small amount of extra PVAc was formed. This outcome suggests that complete polymerisation occurs soon after $6 \mathrm{~h}$. The $18 \mathrm{~h}$ polymerisation condition was chosen to ensure polymerisation had gone to completion to maximise the amount of carbon formed. The increased carbon content with polymerisation time is also reflected in the XRD patterns of calcined PVAcB powders formed at different polymerisation times as shown in Fig. 7.

With free radical polymerisation, the formation of high molecular weight polymer occurs immediately upon initiation, and under ideal conditions, the molecular weight of the polymer remains unchanged throughout the course of polymerisation [22]. GPC analysis of 1, 6 and $18 \mathrm{~h}$ polymerised PVAc shows decreased values for $M_{p}$ and $M_{w}$ with increased polymerisation time-contrary to expectation (Table 2). This effect may be due to gradual contamination of the system by $\mathrm{O}_{2}$ which results in radical pacification through the formation of peroxides [23]. Contamination from atmospheric oxygen may occur through the seals of the reaction vessel, especially at longer polymerisation time. GPC chromatograms of 1 , 6 and $18 \mathrm{~h}$ polymerised PVAc also show evidence of some low molecular weight species which suggests the presence of some residual VA monomer and PVAc oligomers.

DSC and TGA characterisation was carried out on three samples: (a) pure $\mathrm{H}_{3} \mathrm{BO}_{3}$, (b) $1 \mathrm{~h}$ polymerised PVAc and (c) $1 \mathrm{~h}$ polymerised PVAc in the presence of $\mathrm{H}_{3} \mathrm{BO}_{3}$. DSC data show a peak at $225{ }^{\circ} \mathrm{C}$ that is not present in either the pure $\mathrm{H}_{3} \mathrm{BO}_{3}$ sample or the 1 hour PVAc sample, indicating that complexation between the $\mathrm{H}_{3} \mathrm{BO}_{3}$ and the polymer has occurred (Fig. 2). This mechanism is also suggested by the small hump observed in the TGA data shown in Fig. 3. TGA data was also used to identify the temperature required for pre-treatment of precursor condensates. As shown in Fig. 3, no further weight loss is observed above $500^{\circ} \mathrm{C}$. Thus, a temperature of $550{ }^{\circ} \mathrm{C}$ is considered a suitable pre-treatment temperature to ensure sufficient decomposition of the sample before calcination.

\subsection{PVAcB powder Composition and Morphology}

PVAcB powders calcined without pre-treatment predominantly contain residual carbon, exhibit minimal $\mathrm{B}_{4} \mathrm{C}$ and contain no $\mathrm{H}_{3} \mathrm{BO}_{3}$ (Fig. 9). Furthermore, PVAcB powder pre-treated at $450{ }^{\circ} \mathrm{C}$ exhibits a similar but less dramatic increase in residual carbon compared with PVAcB powder pre-treated at $550{ }^{\circ} \mathrm{C}$. This outcome suggests that the carbon matrix is not available to react optimally with boron under these conditions, and thus, results in loss of boron by volatilisation of gaseous boron-oxide species [24, 25]. This volatilisation is attributed to the presence of excess oxygen in the PVAc which reacts preferentially with the reducing $\mathrm{CO}$ gas atmosphere (Eq. (4)). After dehydration of $\mathrm{H}_{3} \mathrm{BO}_{3}$ in the PVAcB powder has occurred, the carbothermal reaction can be represented by:

$$
2 \mathrm{~B}_{2} \mathrm{O}_{3}+7 \mathrm{C} \rightarrow \mathrm{B}_{4} \mathrm{C}+6 \mathrm{CO}
$$

The overall carbothermal process takes place in two stages, the first of which is the reduction of $\mathrm{B}_{2} \mathrm{O}_{3}$ by $\mathrm{CO}$, followed by the reaction of elemental boron with carbon to form $\mathrm{B}_{4} \mathrm{C}$ as shown in Eqs. (2) and (3):

$$
\begin{gathered}
\mathrm{B}_{2} \mathrm{O}_{3}+3 \mathrm{CO} \rightarrow 2 \mathrm{~B}+3 \mathrm{CO}_{2} \\
4 \mathrm{~B}+\mathrm{C} \rightarrow \mathrm{B}_{4} \mathrm{C}
\end{gathered}
$$


If excess oxygen is present in the precursor carbon matrix, reduction by $\mathrm{CO}$ will prefer reaction with the matrix leaving $\mathrm{B}_{2} \mathrm{O}_{3}$ unreduced:

$$
\mathrm{B}_{2} \mathrm{O}_{3}+\mathrm{CO}+\mathrm{O}_{\text {(matrix) }} \rightarrow \mathrm{B}_{2} \mathrm{O}_{3}+\mathrm{CO}_{2}
$$

By comparing Eqs. (2) and (4), it can be seen that the presence of excess oxygen within the carbon matrix greatly hinders the carbothermal reaction process and leads to boron volatilisation as the boron component is insufficiently reduced at high temperature. For this reason, a pre-treatment stage is utilised to remove residual oxygen from the polymer matrix before calcination.

ATR-FTIR of unwashed pre-treated powders shows a transmittance spectrum that matches $\mathrm{H}_{3} \mathrm{BO}_{3}$ (Fig. 6). This spectrum shows no attributes for carbon despite being present in large quantities. Since the penetration depth of an IR signal is limited, the spectrum in Fig. 6 suggests that $\mathrm{H}_{3} \mathrm{BO}_{3}$ forms as a homogeneous coating on the carbon matrix. This finding is contrary to earlier work on solution based methods $[3,6,7,8,18]$ in which it is proposed that boron at this stage of processing is $\mathrm{B}_{2} \mathrm{O}_{3}$. Based on the ATR-FTIR data shown in Fig. 6, and the well-known hygroscopic nature of $\mathrm{B}_{2} \mathrm{O}_{3}$ [26], the precursor, once exposed to air after pre-treatment, will rapidly reabsorb water to form $\mathrm{H}_{3} \mathrm{BO}_{3}$ as per the reaction shown in Eq. (5). The PVAcB powder XRD pattern shown in Fig. 5 matches the literature data for $\mathrm{H}_{3} \mathrm{BO}_{3}$ and supports this interpretation of the ATR-FTIR spectrum shown in Fig. 6.

$$
\mathrm{B}_{2} \mathrm{O}_{3}+3 \mathrm{H}_{2} \mathrm{O} \rightarrow 2 \mathrm{H}_{3} \mathrm{BO}_{3}
$$

SEM images of pre-treated PVAcB powder before washing (Fig. 4a and Fig. 4b) reveal a porous structure with pore sizes ranging from $100 \mathrm{~nm}$ up to $1 \mu \mathrm{m}$. The pore structure is very similar to that reported by Kakiage et al. [3] for condensed precursors. A typical SEM image of pre-treated PVAcB powder after washing can be seen in Fig. 4c. Comparison with the same area without washing (Fig. 4b) shows that the pores are of similar dimension. These images, as well as the ATR-FTIR results detailed above, show that the boron precursor is $\mathrm{H}_{3} \mathrm{BO}_{3}$ rather than $\mathrm{B}_{2} \mathrm{O}_{3}$, and appears to create a surface coating inside the pores of the carbon matrix. Fine strings of $\mathrm{H}_{3} \mathrm{BO}_{3}$ with diameters of less than $\sim 10 \mathrm{~nm}$ are observed (see white arrow in Fig. 4b). This description of the reaction mechanism is different from that proposed by Kakiage et al. [3] who consider that pores in their precursor material are filled with $\mathrm{B}_{2} \mathrm{O}_{3}$. Equivalent SEM images of the polyvinyl alcohol $/ \mathrm{H}_{3} \mathrm{BO}_{3}$ powder prepared by Kakiage et al. or analyses of the precursor powder before washing are not available for comparison.

Unwashed pre-treated PVAcB powders also exhibit surface cracking of the carbon matrix. These surface cracks are attributed to water absorption by $\mathrm{B}_{2} \mathrm{O}_{3}$ after exposure to air which causes swelling as it hydrates to form $\mathrm{H}_{3} \mathrm{BO}_{3}$ (Eq. (5)). After washing with hot water, these cracks appear to 'heal' as they close on the surface, as highlighted by the red arrows in Fig. $4 \mathrm{~b}$ and Fig. 4c.

\subsection{Treatment Atmosphere for PVAcB Powders}

The treatment atmosphere of PVAcB powders is found to have a significant effect on precursor composition, specifically carbon content, and hence different atmospheric treatment conditions were trialed and analysed to ascertain the optimum pre-treatment conditions to form near carbon-free $\mathrm{B}_{4} \mathrm{C}$.

\subsubsection{Partial Vacuum}

Fig. 7 shows XRD traces of PV1-1-550, PV6-1-550 and PV18-1-550 PVAcB powders after calcination at $1,400{ }^{\circ} \mathrm{C}$ for $1 \mathrm{~h}$ under $3 \mathrm{~L} / \mathrm{m}$ Ar flow. The carbon peak increases with increased polymerisation time. This trend shows that control of carbon content in PVAcB powder is achieved by variation of the polymerisation time. Heat treatment for a further $1 \mathrm{~h}$ at $1400{ }^{\circ} \mathrm{C}$ results in reaction completion for all samples as seen in Fig. 8. PV6-1-550 PVAcB powder calcines to nearly carbon-free $\mathrm{B}_{4} \mathrm{C}$. This result indicates that $6 \mathrm{~h}$ is the optimum polymerisation time to generate sufficient PVAc to balance the requirements of the carbothermal reaction under partial vacuum conditions. 
In contrast, PV1-1-550 PVAcB powder gives $\mathrm{B}_{4} \mathrm{C}$ with residual $\mathrm{H}_{3} \mathrm{BO}_{3}$ impurity because there is not enough carbon present for reaction under these conditions. In addition, an $18 \mathrm{~h}$ polymerisation time gives $\mathrm{B}_{4} \mathrm{C}$ with a large amount of residual carbon and no residual $\mathrm{H}_{3} \mathrm{BO}_{3}$. This outcome is due to the excess carbon present in the $18 \mathrm{~h}$ polymerised $\mathrm{PVAcB}$ powder. Fig. 11 shows XRD patterns for PV6-1-550 PVAcB powder calcined at $1,250{ }^{\circ} \mathrm{C}$ for $1,2,3$ and $4 \mathrm{~h}$ under $3 \mathrm{~L} / \mathrm{m}$ Ar flow. $\mathrm{B}_{4} \mathrm{C}$ starts to form after $1 \mathrm{~h}$, and the reaction has gone to completion after $4 \mathrm{~h}$. Minimal residual carbon and no $\mathrm{H}_{3} \mathrm{BO}_{3}$ is observed in the final $\mathrm{B}_{4} \mathrm{C}$ product after $4 \mathrm{~h}$ at $1,250{ }^{\circ} \mathrm{C}$.

$\mathrm{B}_{4} \mathrm{C}$ calcinations taken to completion that contain excess carbon (PV18-1-550 PVAcB powder calcined at $1,400{ }^{\circ} \mathrm{C}$ for $2 \mathrm{~h}$ in this example) exhibit regions of hollow spherical carbon shells attached to the surface of the $\mathrm{B}_{4} \mathrm{C}$ particles (Fig. 13b insert). The average particle size of these $\mathrm{B}_{4} \mathrm{C}$ powders (Fig. 13b) is also noticeably smaller compared with near carbon-free $\mathrm{B}_{4} \mathrm{C}$ powders owing to the increased $\mathrm{H}_{3} \mathrm{BO}_{3}$ dispersion that results from the extra carbon presence from the $18 \mathrm{~h}$ polymerisation time. Free carbon is also observed as independent agglomerates throughout the sample.

\subsubsection{Full Ar Flow}

The presence of residual carbon in the XRD pattern of A6-1-550 in Fig. 10 is due to the absence of vacuum in the pre-treatment stage (Section 4.3.3). Because of this effect, the polymerisation time can be reduced significantly to achieve the required amount of carbon for optimum phase formation without residual $\mathrm{H}_{3} \mathrm{BO}_{3}$ and minimal residual carbon under atmospheric pressure pre-treatment conditions. The reduced calcination time of A6-1-550 (1 h compared with $2 \mathrm{~h}$ for PV6-1-550 and V6-1-550) to reach complete $\mathrm{B}_{4} \mathrm{C}$ phase formation can be attributed to excess carbon that is present in the PVAcB powder. As reported previously $[6,7]$, homogeneity of the boron component within the precursor powder is increased by the presence of excess carbon. Although this effect is desirable, it is not practical as it results in excess carbon impurity in the final product.

Fig. 12 shows XRD patterns of $1 \mathrm{~h}$ polymerisation PVAcB powder pre-treated at $550{ }^{\circ} \mathrm{C}$ for $2 \mathrm{~h}$ in full $\mathrm{Ar}$ flow (A1-2-550) after final calcination at $1,400{ }^{\circ} \mathrm{C}$ for 1 and $2 \mathrm{~h}$ under $3 \mathrm{~L} / \mathrm{m}$ Ar flow. After $1 \mathrm{~h}$, a significant amount of $\mathrm{B}_{4} \mathrm{C}$ formation has occurred with carbon and $\mathrm{H}_{3} \mathrm{BO}_{3}$ phases still present. After $2 \mathrm{~h}, \mathrm{~B}_{4} \mathrm{C}$ phase formation has gone to completion. At $2 \mathrm{~h}$ calcination time, almost carbon-free $\mathrm{B}_{4} \mathrm{C}$ with no $\mathrm{H}_{3} \mathrm{BO}_{3}$ component is achieved, indicating that a $1 \mathrm{~h}$ polymerisation time is optimum for $\mathrm{PVAcB}$ powders pre-treated under $3 \mathrm{~L} / \mathrm{min}$ full Ar flow conditions. The increased calcination time required for A1-2-550 PVAcB powder compared to A6-1-550 PVAcB powder (an extra $1 \mathrm{~h}$ at $1,400{ }^{\circ} \mathrm{C}$ ) is due to the reduced amount of carbon in the PVAcB powder from a shorter polymerisation time $(1 \mathrm{~h})$.

SEM images of near carbon-free $\mathrm{B}_{4} \mathrm{C}$ calcined from A1-2-550 PVAcB powder at $1,400{ }^{\circ} \mathrm{C}$ for $2 \mathrm{~h}$ show interconnected particles with sizes ranging from sub-micrometer to $\sim 10 \mu \mathrm{m}$ (Fig. 13a). Some rod-like structures are also dispersed throughout the agglomerates. Free carbon is not observed on the surface of the $\mathrm{B}_{4} \mathrm{C}$ grains nor as separate particles within the sample. These same observations are true for SEM images of near carbon-free $\mathrm{B}_{4} \mathrm{C}$ calcined from PV6-1-550 PVAcB powder.

\subsubsection{Full Vacuum}

Full vacuum pre-treatment $\left(1 \times 10^{-3}\right.$ bar absolute pressure, no Ar flow) was carried out at $550,{ }^{\circ} \mathrm{C}$ for $1 \mathrm{~h}$ on $6 \mathrm{~h}$ polymerised PVAcB powder (V6-1-550) for comparison with $6 \mathrm{~h}$ polymerised PVAcB powder pre-treated with partial vacuum and full Ar flow conditions (PV6-1-550 and A6-1-550 respectively). Fig. 10 shows a comparison of the XRD patterns collected for these three precursor materials taken to $\mathrm{B}_{4} \mathrm{C}$ phase formation completion. Product calcined from V6-1-550 PVAcB powder shows no residual carbon and a residual $\mathrm{H}_{3} \mathrm{BO}_{3}$ component. Product formed from PV6-1-550 PVAcB powder shows no residual components. Product from A6-1-550 PVAcB 
powder shows a residual carbon component. From these results, it can be concluded that applying vacuum to the pre-treatment stage removes extra carbon from the PVAcB powder and the amount removed is dependent on vacuum conditions. This effect can be accounted for by the low vapour pressure of residual monomer at higher temperature resulting in removal of the monomer and other short chain polymer moieties. The presence of these short chain polymer fragments is confirmed via GPC analysis (Section 4.1).

\subsection{Residual Carbon}

As shown earlier, the polymerisation time is optimized to minimize the residual carbon content via appropriate balance of reactants for subsequent carbothermal reaction. Raman spectra shown in Fig. 14 provide useful insight on the influence of polymerisation time and the form of carbon in the final $\mathrm{B}_{4} \mathrm{C}$ product. As mentioned previously, independent carbon agglomerates, attached to the $\mathrm{B}_{4} \mathrm{C}$ grains or as independent particles, are not observed in SEM images of near carbon-free $\mathrm{B}_{4} \mathrm{C}$ samples (calcined from PV6-1-550 and A1-2-550 PVAcB powder), yet a small amount of carbon is detected via XRD analysis. Raman investigation reveals that this small amount of residual carbon is present on the surface of the $\mathrm{B}_{4} \mathrm{C}$ grains. Furthermore, the amount of carbon detected varies from grain to grain, but the typical amounts are within the ranges shown by the peak intensities in Fig. 14.

In the case of $\mathrm{B}_{4} \mathrm{C}$ calcined from PV1-1-550 PVAcB powder ( $1 \mathrm{~h}$ polymerisation), low amounts of $\mathrm{B}_{4} \mathrm{C}$ and no residual carbon or $\mathrm{H}_{3} \mathrm{BO}_{3}$ is observed after calcination (compare XRD intensities in Fig. 8) due to poor homogeneity of the boron and carbon components in the precursor as well as the proclivity of $\mathrm{B}_{2} \mathrm{O}_{3}$ to readily volatilize. Despite this, the Raman spectra show that small amounts of residual carbon are still present on the surface of the $\mathrm{B}_{4} \mathrm{C}$ grains. $\mathrm{B}_{4} \mathrm{C}$ calcined from PV18-1-550 PVAcB powder shows increased carbon content which is consistent with XRD and other data shown previously and is due to an increased polymerisation time.

As noted in Section 3.4.2, Raman spectra can provide useful qualitative indications of sample stoichiometry [19]. Near carbon-free $\mathrm{B}_{4} \mathrm{C}$ calcined from PV6-1-550 PVAcB powder shows a consistent intensity of the peaks at $270 \mathrm{~cm}^{-1}$ and $320 \mathrm{~cm}^{-1}$ over all Raman spectra obtained from all grains. This outcome, examples of which are shown in Fig. 14, indicates that the quality-or stoichiometry-of the $\mathrm{B}_{4} \mathrm{C}$ structure formed by this synthesis is consistent across all individual grains. However, the Raman spectra for $\mathrm{B}_{4} \mathrm{C}$ samples calcined from both PV18-1-550 and PV1-1-550 PVAcB powder show significant variations in the intensities of peaks at $270 \mathrm{~cm}^{-1}$ and $320 \mathrm{~cm}^{-1}$ for different grains. Thus, the stoichiometry of $\mathrm{B}_{4} \mathrm{C}$ powder containing residual impurities is variable within the sample, while near carbon-free $\mathrm{B}_{4} \mathrm{C}$ powder shows consistency in structural carbon content and hence overall stoichiometry throughout the entire sample.

\section{Conclusions}

By polymerising VA monomer in the presence of dissolved $\mathrm{H}_{3} \mathrm{BO}_{3}$ in methanol, the amount of carbon available for reaction in PVAcB powders can be controlled via the polymerisation time. Increased dispersion of the precursor phase is enhanced by the presence of excess carbon as unreacted VA monomer in solution. This feature affords excellent homogeneity of the reactants without requirement for excess carbon in the PVAcB powder. Using this technique, near carbon-free $\mathrm{B}_{4} \mathrm{C}$ powders are formed after $2 \mathrm{~h}$ at $1,400{ }^{\circ} \mathrm{C}$ as well as after four hours at $1,250{ }^{\circ} \mathrm{C}$ without the need for carbon removal from the $\mathrm{PVAcB}$ powder via pyrolysis in air.

\section{Acknowledgments}

The author would like to gratefully acknowledge Mitchell De Bruyn, Tony Raftery, Alison Chou, Llew Rintoul, John Colwell and James Blinco for useful discussions and assistance with characterisation as well 
as the Institute for Future Environments for provision of a Ph.D. scholarship.

\section{References}

[1] Thevenot, F., and Euro, J. 1990. Ceram. Soc. 6: 205-225.

[2] Alizadeh, A., Taheri-Nassaj, E., and Ehsani, N. 2004. J. Euro. Ceram. Soc. 24: 3227-3234.

[3] Kakiage, M., Yanagidani, S., Yanase, I., and Kobayashi, H. 2011. J. Ceram. Soc. Jpn. 119: 422-5.

[4] Benton, S., David, M. 1975. Methods for preparing boron carbide articles. US Patent 3914 371, filed Dec 27, 1973, and issued Oct 21, 1975.

[5] Bigdeloo, J., and Hadian, A. 2009. Inert. J. Rec. Tren. Eng. 1: 176-180.

[6] Kakiage, M., Tahara, N., Yanase, I., and Kobayashi, H. 2011. Mater. Lett. 65: 1839-1841.

[7] Kakiage, M., Tominaga, Y., Yanase, I., and Kobayashi, H. 2012. Powd. Tech. 221: 257-263.

[8] Tahara, M., Kakiage, M., Yanase, I., and Kobayashi, H. 2013. J. Alloy. Comp. 573: 58-64.

[9] Krishnarao, J., Subrahmanyam, J., Kumar, T., and Ramakrishna, V. J. 2010. Alloy. Comp. 496: 572-6.

[10] Junga, C., Leeb, M., and Kim, C. 2004. Mater. Lett. 58: 609-614.

[11] Weimer, A., Roach, R., and Haney, C. 1991. Am. Inst. Chem. Eng. 37: 759-768.
[12] Weimer, A., Moore, W., Roach, R., Hitt, J., and Dixit, R. 1992. J. Am. Ceram. Soc. 75: 2509-2514.

[13] Khanra, A. 2007. Bull. Mater. Sci. 30: 93-6.

[14] Sinha, A., Mahata, T., and Sharma, B. 2002. J. Nucl. Mater. 301: 165-9.

[15] Hadian, A., and Bigdeloo, J. 2008. J. Mater. Eng. Perform. 17: 44-9.

[16] Najafi, A., Golestani-Farda, F., Rezaiea, H. R., and Ehsania, N. 2011. J. Alloy. Comp. 509: 9164-9170.

[17] Najafi, A., Golestani-Farda, F., Rezaiea, H. R., and Ehsania, N. 2012. Ceram. Int. 38: 3583-9.

[18] Yanase, I., Ogawara, R., and Kobayashi, H. 2009. Mater. Lett. 63: 91-3.

[19] Tallant, D. R., Aselage, T. L., Campbell, A. N., and Emin, D. 1988. J. Non-Cryst. Solids. 106: 270-3.

[20] Shirai, K., and Emura, S. 1997. J. Solid State Chem. 133: 93-6.

[21] Ferrari, A. C., and Robertson, J. 2000. Phys. Rev. B. 61: 14095-14107.

[22] Odian, G. 2004. Principles of Polymerization, Fourth Edition. New Jersey: J. Wiley \& Sons.

[23] Allen, P. W. 1955. J. Polym. Sci. 17: 156-8.

[24] Rentzepis, P., White, D., and Walsh, P. 1960. J. Phys. Chem. 64: 1784-7.

[25] Lamoreaux, R., and Hildenbrand, D. 1986. J. Phys. Chem. Ref. Data. 16: 419-443.

[26] Perez-Enciso, E., Ramos, M., and Vieira, S. 1997. Phys. Rev. B. 56: 32-35. 